\title{
Psychological Skills in Relation to Academic Achievement through Swimming Context
}

\author{
Manal M. Bayyat*1, Samira M. Orabi', Assefa Al-Tarawneh², Sofyan Alleimon ${ }^{3}$ \\ 'School of Sport Sciences, University of Jordan, Amman, Jordan; \\ ${ }^{2}$ Ministry of Education, Amman, Jordan; \\ ${ }^{3}$ National University College of Technology, Amman, Jordan \\ *Email:mabayyat@yahoo.com; m.bayyat@ju.edu.jo
}

\begin{abstract}
This study aimed to investigate: (1) the level of psychological skills among students enrolled in swimming courses at the Physical Education faculties in the Jordanian Universities. (2) the relation between their psychological skills and academic achievement. (3) the differences in these psychological skills according to gender. The descriptive approach was used to conduct this study. The study sample consisted of (260) male and female students enrolled in intermediate and advanced level swimming courses at the School of Sport Sciences/ University of Jordan. Students' final academic achievement records in addition to the "Life skills through swimming context" scale was used to collect required data. The results of the statistical analysis revealed an average level of psychological skills, significant differences in psychological skills level in favor of female students, A level students, and JU students, and a positive significant relation between psychological skills and academic achievement. In conclusion, it is important to design comprehensive psychological skills-based study plans for swimming courses and in different sports fields. Also, to conduct specified training and guidance courses in this domain to improve psychological skills, teaching competencies and academic achievement.
\end{abstract}

Keywords: psychological skills, academic achievement, swimming courses.

\section{INTRODUCTION}

Psychological skills (PS) are a group of skills and abilities that enhances peoples' performance and achievement (Ay, 2019; Huzair, 2017). These skills are positively related to sport participation levels (Abdel Wahhab, 2019). Weinberg \& Gould, (2018) suggested that PS includes a whole set of trainable skills including emotional control and self-confidence. Self-confidence improves athletic performance (Maqableh, 2019), and along with emotional control and concentration, these skills play an active role in the Olympian's performance (Gould et al., 2009). Motivation is also considered a performance predictor of technical skills (Forsman et al., 2016; Kannekens et al., 2011). Consequently, academic achievement reflects the learner's accomplishment of specific goals by the end of an academic experience in a determined amount of time (Wirthwein et al., 2014).

Psychological skills can be studied and taught through sport contexts (Danish, 1996). Sport psychologists believe that sports are a vehicle for healthy development (Holt et al., 2008). Therefore, the swimming context can be a rich environment to help students develop such skills (Bayyat et al., 2016). Ay (2019) has revealed a moderate level of psychological skills for students enrolled in swimming classes. And AlDababseh et al., (2017) concluded a positive relation between psychological compatibility and academic achievement while learning free-style swimming skills. 
All schools of sports sciences at the universities of Jordan offer mandatory, reliable, and valid swimming programs. Students enroll in one of three swimming courses consequently: the basic, intermediate, and advanced level. Each student must pass the previous level to be able to enroll in the next level. In our pursuit to advance the literature in sportsmen development, the authors of this study have decided to investigate the psychological skills of students through the swimming context at Jordanian universities. To expand our research, we seek to examine the following: (1) The psychological skills of students enrolled in intermediate and advanced swimming courses at the schools of sports sciences in Jordanian universities; the University of Jordan (JU), Yarmouk University (YU) and Mutah University (MU) (2) the differences in students' psychological skills (dependent variables) according to socio-demographic variables (independent variables); gender, swimming course level (intermediate and advanced swimming courses), academic achievement level (A (excellent), B (very good), C (Good), D (fair), E (poor) and F (very bad) )and university (JU, YU, and MU), And (3) the relation between students' psychological skills and their academic achievement.

\section{METHODOLOGY}

The descriptive methodology approach was used to fulfill the objectives of the study, we chose to examine students in the intermediate and advanced level of swimming courses conducted at sports schools of three state universities in Jordan; JU, located in the capital of Jordan Amman, YU, located in the northern city of Irbid and MU, located in the southern city of Kerak. Through intermediate course level, students attend a one-hour class/three days a week for four months, while those enrolled in the advanced course level attend a two-hours class/three days a week for four months.

Each course level has its Students' Intended Learning Outcomes that focus on developing swimming skills. By the end of the intermediate level, students are expected to show improvement in stroke technique of the front and back crawl, breaststroke and butterfly stroke, and some basic life-saving skills. Also, by the end of the advanced level, students are expected to advance the quality of all four strokes, and increase the competency of the core aquatic skills and teach/ train different swimming skills.

\subsection{The Sample of the study}

The population of this study was undergraduate male and female students attending both intermediate and advanced swimming courses. They consisted of $(n=314)$ students enrolled at the schools of Sport Sciences at three state universities: JU 168 (53.5\%), YU 123 (39.2\%), and MU 23 (7.3\%). The Participants were an opportunity sample of 260 students, out of which 133 (51.2\%) were male and 127 (48.9\%) were female distributed at the JU, YU, and MU as follows; 101 (38.9\%) (42 males and 59 females), 137 (52.7\%) (82 males and 55 females) and 22 (8.5\%) (9 males and 13 females) respectively; $202(77.7 \%)$ were intermediate level students and $58(22.3 \%)$ were advanced level. Their mean age was $19.8 \pm 1.27$, and they all voluntarily participated in this study.

\subsection{Instrumentation}

\subsubsection{Development of the "Psychological Skills Questionnaire."}

To collect data related to students' psychological skills, we needed to develop and validate a questionnaire. First, we reviewed literature related to psychological skills in psychology and sport psychology fields (AlGamdi, 2007; Awad, 2010; Ay, 2019; Wahdan, 2011; Zaki, 2010). Secondly, we identified the psychological skills related to the swimming context such as; leadership, emotional 
stability, sport achievement motivation, self-confidence, stress management, and attention. Then, we generated a 40 items-questionnaire reflecting the psychological skills previously mentioned by applying both deductive and inductive methods. The items were clear, understandable, reflect the real-life experience of the study population, and not too long in structure.

\section{Content validity}

For content validation, the scale was reviewed and assessed by eight qualified expert judges from different related fields (sport psychology, swimming, teaching methodology, scientific research methodology, and kinesiology). They were asked to give their opinion of the suggested PS content representation, their relatedness, clarity, and structure of items.

According to the judges' reviews, we omitted both leadership and emotional stability domains, in addition to several items throughout the questionnaire. We rephrased some items and added others. Again, the scale was reviewed by four judges, who agreed on $80 \%$ of the items. Thus, the final version of the "Psychological Skills Questionnaire" questionnaire evolved consisting of four domains including 28 items as follows;

Sport achievement motivation consisted of 8 items $(1,9,10,13,17,20,25,27)$.

Self-confidence consisted of 8 items $(3,4,8,11,18,21,26,28)$.

Stress-management consisted of 6 items $(2,5,7,14,16,24)$.

Attention consisted of 6 items (6,12, 15, 19, 22, 23). See Appendix (1)

Construct validity

Table (1) reflects the correlation coefficients of the 28 items of the four domains, acceptable correlation levels of $0.609-0.869$ reflect the construct validity of the questionnaire.

\section{Discriminant validity}

To ensure that each domain should reflect a different psychological skill, we needed to check that subscales that should not be related to each other will not be or correlate with a minimum degree. Table (2) supports the discriminant validity between the subscales of the "Psychological Skills" questionnaire. We applied Fornel and Larcker criterion to assess discriminant validity (AbHamid, 2018). Correlation coefficients ranged between .71 and .75. They were all under the 0.85 value.

\section{Reliability}

For reliability field testing, we distributed the questionnaire to a random sample of 30 students attending swimming classes as target population judges outside of the study sample. They voluntarily and willingly responded to the questionnaire. The alpha reliability coefficient for all four domains was calculated. A score ranged between .93 and .98 reflected that the scale was reliable.

The "Psychological Skills" questionnaire was rated on a five-point Likert type scale from (1) (never) to (5) (always), with a midpoint of (3) for the (moderately), (2) for (occasionally), and (4) for (usually). The estimated answer time was between 15-20 minutes.

The applicated version of the "Psychological Skills" questionnaire was now ready to be distributed to the participants of the study. Participants were advised to ask for clarification of any item when needed.

Internal Reliability: we calculated the Cronbach alpha of each domain and the total score to check the internal consistency of the items within each domain, for all participation responses. All subscales were internally reliable with an alpha coefficient ranging between .813 and .917 . According to Taber, (2018) these figures are considered high, see table (3).

A classification criterion for participants' responses based on the five-point Likert type scale was determined as follows; 1-2.33 (low), 2.34-3.66 (moderate), 3.67-5 (high). 


\subsubsection{Students' academic achievement:}

To calculate students' academic achievement, the instructors of the swimming courses conducted a valid and reliable assessment as a pre-midterm, midterm, and final exam throughout the semester, see Appendix (2). The assessment included performance tests and theoretical tests (paper and pencil tests) for each level. All tests had proved to be reliable; Cronbach alpha ranged between 0.83 and 0.88 . Final grades were calculated out of 100 for all study sample, then converted to alphabets (A, B, C, D, E, F) reflecting academic achievement level as follows; (90-100 (A; excellent), 80-89 (B; very good), 70-79 (C, Good), 60-69 (D, fair), 50-59 (E; poor) and < 50 (F; very bad)).

\subsection{Data Collection}

The primary population of the study was 314 students, out of which an opportunity sample of 30 students outside the study sample responded to the 28 items instrument for reliability and validation purposes. The questionnaire was then distributed to 284 students by the second and third authors, 24 questionnaires were illuminated for insufficient data, which leaves us with 260 participants (83\% percent of the population), we asked the students to carefully read and answer the "Psychological Skills" questionnaire items, and check the answer that mostly corresponds to them, we advised them to answer all items as possible, and assured them that their responses would be anonymous and for scientific research purposes only. We appreciated their time, effort, and voluntary contribution. The study was conducted during the first semester of the academic year 2019/2020. Permissions and ethical approvals were obtained.

As for the students' academic achievement data, swimming instructors, in cooperation with the authors of the study to achieve reliability and consistency, had concluded all required premidterm, midterm, and final tests. During the assessment process, swimming instructors tended to be fair, avoid stereotyping and biases, and students were advised to demonstrate their best.

\subsection{Analyzing of Data}

To fulfill the first objective of the study, descriptive data were generated to study the nature of psychological skills among the students of the swimming courses (Means and standard deviation). Then, we verified that the distribution of the collected data did not show any evidence of skewness or kurtosis, which means that the distribution was roughly symmetrical and not too flat or too peaked. An independent-sample t-test was conducted to study the differences according to gender and swimming course level (intermediate and advance swimming courses). (ANOVA) was conducted to investigate the differences according to academic achievement level ( A, B, C, D, E, and F) and university (JU, YU, and MU), and the Pearson correlation coefficient was used to examine the relation between the psychological skills and the students' academic achievement level. A p-value of $\leq 0.05$ was considered significant. All analyses were carried out using SPSS, version 27.

\section{RESULTS}

Results of descriptive statistics indicated that all four psychological skills of the participants were at a moderate level. Students thought that self-confidence $(M=3.64(0.72), R I=72.8 \%)$ was the most acquired psychological skill, followed by sport achievement motivation, attention, and stress management.

Table 5 shows students' moderate level of confidence $(M=3.64(0.72), R I=72.8)$, most of the domain items were moderate except for three high-level items, which were; "I manage my time effectively while in class," "I am always ready to perform during the class," and "I feel relaxed 
and reassured when the swimming class starts"; $(M=3.74(0.94), R I=74.8),(M=3.73(0.98)$, $\mathrm{RI}=74.6)$, and $(\mathrm{M}=3.73(0.91), \mathrm{RI}=74.6)$ respectively.

Table 6 shows students' moderate level of sport achievement motivation $(M=3.61(0.67)$, all of the domain items were moderate except for one high-level item, which was; "I work hard to fix my mistakes right away"; $(\mathrm{M}=3.73(0.85), \mathrm{RI}=74.6)$.

Followed by a moderate level of the attention domain $(\mathrm{M}=3.56(0.67), \mathrm{RI}=71.2)$ as shown in table 7, all domain items were moderate with no exception.

And finally, in the stress-management domain $(M=3.51(0.65), R I=70.2)$, tables 8 show that all items were at a moderate level.

To fulfill the second objective of this study regarding the differences in psychological skills according to socio-demographic variables. The results were as follows;

\section{Gender}

By comparing psychological skills between male and female participants, results revealed significant differences in favor of female participants. On the psychological skills scale, female students reported higher levels of sport achievement motivation $(\mathrm{t}(260)=3.99, \mathrm{p}=.000)$, self-confidence $(\mathrm{t}$ $(260)=3.93, \mathrm{p}=.000)$, stress-management $(\mathrm{t}(260)=4.41, \mathrm{p}=.000)$, and attention $(\mathrm{t}(260)=4.31$, $\mathrm{p}=.000)$ compared to their male peers, see Table (9).

Swimming course level

By comparing psychological skills according to swimming course level, results revealed a significant difference in favor of students of the advanced swimming course. They reported higher levels of sport achievement motivation $(\mathrm{t}(260)=3.25 . \mathrm{p}=.001)$, stress-management $(\mathrm{t}(260)=2.81$, $\mathrm{p}=.005)$, and attention $(\mathrm{t}(260)=3.33, \mathrm{p}=.001)$ compared to their peers of the intermediate swimming classes, see Table (10).

Academic achievement level

Results related to academic achievement level revealed significant difference in sport achievement motivation, self-confidence, stress-management, and attention; $F(5,254)=3.95, p=0.002$ and $\mathrm{F}(5,254)=5.59, \mathrm{p}=0.000, \mathrm{~F}(5,254)=6.21, \mathrm{p}=0.000, \mathrm{~F}(5,254)=4.37, \mathrm{p}=0.001$ respectively. Post hoc analyses using the Scheffé post hoc criterion for significance indicated that; sport achievement motivation, self-confidence, stress-management, and attention were significantly higher in the academic achievement level $(\mathrm{A})(\mathrm{M}=3.91, \mathrm{SD}=0.66),(\mathrm{M}=3.98, \mathrm{SD}=0.68)$, $(\mathrm{M}=3.91, \mathrm{SD}=0.57),(\mathrm{M}=3.93, \mathrm{SD}=0.59)$ than the $(\mathrm{E})$ group $(\mathrm{M}=3.23, \mathrm{SD}=0.96),(\mathrm{M}=3.09$, $\mathrm{SD}=0.86),(\mathrm{M}=3.08, \mathrm{SD}=0.84),(\mathrm{M}=3.15, \mathrm{SD}=0.82)$ respectively. Also, self-confidence and stress-management were significantly higher in the academic achievement level (B) $(M=3.70$, $\mathrm{SD}=0.65),(\mathrm{M}=3.57, \mathrm{SD}=0.57$ than the $(\mathrm{E})$ group $(\mathrm{M}=3.09, \mathrm{SD}=0.86),(\mathrm{M}=3.08, \mathrm{SD}=0.84$ respectively, see Table (11a-b).

\section{University}

Results related to the university attended revealed significant difference in sport achievement motivation, self-confidence, stress-management, and attention; $F(2,257)=18.24, \mathrm{p}=0.000$ and $\mathrm{F}(2,257)=31.81, \mathrm{p}=0.000, \mathrm{~F}(2,257)=7.30, \mathrm{p}=0.001, \mathrm{~F}(2,257)=22.45, \mathrm{p}=0.000$ respectively. Post hoc analyses using the Scheffé post hoc criterion for significance indicated that; sport achievement motivation, self-confidence, stress-management, and attention were significantly higher in the JU group $(\mathrm{M}=3.90, \mathrm{SD}=0.58),(\mathrm{M}=4.04, \mathrm{SD}=0.57),(\mathrm{M}=3.69, \mathrm{SD}=0.58)$, $(\mathrm{M}=3.88, \mathrm{SD}=0.63)$ than the $\mathrm{YU}(\mathrm{M}=3.42, \mathrm{SD}=0.69),(\mathrm{M}=3.40, \mathrm{SD}=0.72),(\mathrm{M}=3.39$, 
$\mathrm{SD}=0.69),(\mathrm{M}=3.36, \mathrm{SD}=0.63)$ and $\mathrm{MU} \operatorname{group}(\mathrm{M}=3.39, \mathrm{SD}=0.31),(\mathrm{M}=3.34, \mathrm{SD}=0.46)$, $(\mathrm{M}=3.36, \mathrm{SD}=0.45),(\mathrm{M}=3.32, \mathrm{SD}=0.47)$ respectively, see Table $(12 \mathrm{a}-\mathrm{b})$.

To fulfil the third objective of this study regarding the relation between psychological skills and academic achievement. Table 10 shows positive and significant relations between all psychological skills; sport achievement motivation. self-confidence, stress-management, attention, and academic achievement level as follows; sport achievement motivation $(\mathrm{rs}(\mathrm{df})=.16, \mathrm{p}=.011)$, self-confidence $(\mathrm{rs}(\mathrm{df})=.17, \mathrm{p}=.005)$, stress-management $(\mathrm{rs}(\mathrm{df})=.24, \mathrm{p}<.001)$, and attention $(\mathrm{rs}(\mathrm{df})=.20, \mathrm{p}=.001)$. See table 13 .

\section{DISCUSSION}

Results of this study revealed that the participants acquired all four psychological skills at a moderate level. Students agreed that self-confidence was the most acquired psychological skill, followed by motivation, attention, and stress management. Similarly, AlShahed, (2006), Ay, (2019) and AlDababseh et al., (2017) concluded that swimmers acquire moderate levels of self-confidence, attention, and stress management. On the contrary, Boostani, et al (2013) and Yousef, (2015) revealed high levels of psychological skills for Karate players, and for volleyball players. $\mathrm{Chu}$, et al, (2010) found that the psychological skills' levels of table tennis players were low.

Participants of all swimming classes were highly confident and relaxed, they were ready to perform new swimming skills and believed they could manage their time effectively throughout the classes. Yet, they were moderately reassured and thought that their technical abilities enabled them to perform high-level swimming skills and sought to achieve their goals. They approached the swimming pool fearlessly and dealt with unexpected situations during their swimming lessons with moderate confidence. Accordingly, self-confidence was the most acquired psychological skill for swimmers (AlShahed, 2006), and for field training students (Tarawneh, 2016), yet it came in third place for basketball players (Kuraizi, 2008) and fourth for volleyball players (Hatamlah et al., 2011). Nijmah, (2014) emphasized the important role self-confidence play in improving learning and performance.

Sport achievement motivation skill was next in line; results indicated moderate levels of motivation; participants sought to perform difficult swimming tasks; excellency was their main goal. They tried their best, worked hard, and trained for extra hours to improve their swimming skills. They had control over things when responsible and could manage and motivate their teammates. Nevertheless, they were highly motivated to fix any mistakes or difficulties they would encounter immediately.

Following was a moderate level of attention; participants listened carefully to the instructions, focused on all their teammates' performance, they were able to spot their optimum performance or mistakes and were aware of different places in the pool while carrying out the swimming tasks, they even kept track of the time left for class, all at a moderate level. Yeung (2001) and Hadef, (2018) emphasized the importance of self-awareness of abilities, skills, and competencies to maintain attention and focus, and achieve one's goals and tasks. Younes, (2015) concluded that a student gets distracted with too much information and details concerning the presented skill, which might result in lack of his attention and concentration.

Stress management came last at a moderate level; participants felt they could control their emotions and calm down quickly if they got triggered or upset, they were not afraid to perform any difficult swimming skill, they swam calmly, did not fear spectators, and accepted criticism. 
All psychological skills' dimensions of female participants were significant in favor of females compared to their male peers. They were more focused, concentrated, confident, motivated to achieve their goals, and sought to manage their stress. These results are in accord with Hatamlah et al., (2011) who revealed the positive significance of psychological skills in favor of female volleyball players. However, the findings do not support Tarawneh, (2016) and Kumar \& Bhukar (2013) who concluded that field training course male students were positively significant. Nevertheless, AlShahid, (2006) revealed no significant differences in psychological skills according to gender.

Participants enrolled in advanced swimming courses reported higher levels of sport achievement motivation, stress-management, and attention than their peers in the intermediate swimming classes. In contrast, there were no significant differences in self-confidence. This may be attributed to the students' advanced technical and skill level in the advanced swimming course, who have already passed the intermediate swimming course, and were more experienced.

Results related to academic achievement level revealed significant differences in sport achievement motivation, self-confidence, stress-management, and attention. These skills were higher in the academic achievement level (A) compared to the (E) group. Also, self-confidence and stress-management were significantly higher in the academic achievement level (B) compared to the (E) group.

Results related to the university attended revealed significant differences in sport achievement motivation, self-confidence, stress management, and attention in favor of JU group. JU is located in Jordan's capital, Amman, where availability and access to swimming pools for recreational or training courses are more applicable than in other cities in Jordan. Also, the school of sport sciences in JU plays an active role in marketing swimming courses for the community. This result disagrees with Tarawneh (2016) who revealed no significant differences between university students according to self-confidence.

There was a significant positive relation between all psychological skills and academic achievement level. These skills played an active role in learning how to swim. Students' self-confidence and motivation to achieve encouraged them to practice without any fear or hesitation. Attention and concentration skills enhanced their motor learning and training process. Vice versa, good academic achievement would have boosted the students' psychological skills. Moderate levels of psychological compatibility provide swimmers, football players, volleyball players, badminton, and table-tennis players with the appropriate ground of demonstrating competencies, motivation and abilities to express their thoughts and feelings more, which eventually raises their academic achievement (Ay, 2019; Hidaya, 2011; Huzair, 2017 Mohammadzadeh \& Sami, 2014; Zubeidi, 2011).

\section{CONCLUSION}

The purpose of the current study was to examine the psychological skills of students enrolled in intermediate and advanced swimming courses at the schools of sport sciences in Jordanian universities, the differences in students' psychological skills (dependent variables) according to different independent variables; gender, swimming course level (intermediate and advanced swimming courses), academic achievement level and university. And to highlight the relation between students' psychological skills and their academic achievement. The findings indicated a moderate level of psychological skills, significant differences in psychological skills level in favor of female students, A students and JU, and significant positive relation between psychological skills and academic achievement. 


\section{RECOMMENDATIONS}

These findings could be used to design and implement comprehensive psychological skills-based study plans of swimming courses and in different sport fields. Also, to conduct specified training and guidance courses in this domain to improve psychological skills, teaching competencies, and academic achievement.

\section{LIMITATIONS}

A possible limitation in this study is the limited access of students to swimming pools, and the rare occasions students get to practice swimming in their spare time.

\section{References}

Abdul Wahhab, M. (2019). The contribution of the semi-sports games to the development of some psychological abilities of the third intermediate students, unpublished Masters theses, Algeria.

Ab Hamid, M. R., Sami, W., \& Sidek, M. M. (2017, September). Discriminant validity assessment: Use of Fornell \& Larcker criterion versus HTMT criterion. In Journal of Physics: Conference Series (Vol. 890, No. 1, p. 012163). IOP Publishing. https://doi.org/10.1088/1742-6596/890/1/012163

AlDababseh, M.F., Ay, K.M, Abu Al-taieb, M.H., Hammouri, W.Y., \& Abu Areeda, F.S. (2017). The relationship between psychological compatibility and academic achievement in swimming. Journal of Human Sport and Exercise, 12(2), 396-404. https://doi.org/10.14198/jhse.2017.122.16

AlShahed, M. (2006). Psychological Skills for competitive Male and Female Swimmers. Assiut Journal of Science and Arts of Physical Education.2 (23).

Awad, H. (2010). Psychological skills and their relationship to the level of skill performance in some specialized sports activities for students of the Department of Sports Education at the University of Bahrain. The Scientific Journal of Physical Education and Sports, Alexandra University.

Ay, Khitam (2019), Stress Coping Skills and Emotional Intelligence Level in Relation to Academic Achievement among Students Enrolled in Swimming Courses in Faculty of Physical Education at the University of Jordan, Dirast Educational Sciences, University of Jordan, 46.

Bayyat, M. M., Orabi, S. M., \& Abu Altaieb, M. H. (2016). Life Skills Acquired in Relation to Teaching Methods Used Through Swimming Context. Asian Social Science, 12(6), 223. https://doi.org/10.5539/ass.v12n6p223

Boostani, M. H., Boostani, M. A., \& Rezaei, A M. (2013). Sport Psychology in Professional Karate Athletes: give psychological guidelines to improve their act in the competitions. Annals of Biological Research, 4(1):48-52

Chu, C. Y., Lin, J. H., \& Hung, T. M (2010).A Study on Table Tennis Players, Psychogical Skills, Sport Injuries, and Tournament Satisfaction at the $49^{\text {th }}$ Word Championship. International Journal of Table Tennis Sciences, issue(6): 200

Danish, S. J. (1996). Interventions for Enhancing Adolescents Life Skills. The Human Psychologist, 24(3), 365-381. http:// dx.doi.org/10.1080/08873267.1996.9986864

AlGamdi, S. (2007). Psychological skills of swimmers in the Islamic Solidarity Games Championship, unpublished Masters theses, National University, Yemen.

Forsman, H., Blomqvist, M., Davids, K., Liukkonen, J., \& Konttinen, N. (2016). Identifying technical, physiological, tactical and psychological characteristics that contribute to career progression in soccer. International Journal of Sports Science \& Coaching, 11(4), 505-513. https://doi.org/10.1177/1747954116655051

Gould, D., Collins, K., Lauer, L., \& Chung, Y. (2007). Coaching life skills through football: a study of award winning high school coaches. Journal of applied sport psychology, 19(1), 16-37. http://dx.doi.org/10.1080/10413200601113786

Hadef, S. (2018). Occupational pressures and their relationship to achievement motivation among workers of the National Social Security Fund for Non-Wage Workers, unpublished Masters thesis dissertation, Arabi bin Mahdi University, Algeria.

Huzair, J. F. (2017). Psychological skills in relation to the skill performance of Diyali Football Club players. Diyali University, 9 (31).

Hatamlah, M., Alwan, B., \& Maghaera, E., (2011), The Distinguished Spiritual Skills of Volleyball Players and Relationship with Sporting Motivating Traits. Dirast Educational Sciences, University of Jordan, (38)7, p. 2232-2251.

Hidaya, Y. (2011). The Effect of Goal Setting and Mental Imagery Intervention on Badminton Learning Achievement Motor Skill at 10-12 Years Old: The Context of Indonesia. International Journal for Educational Studies, 7 (1)Inc, 129-144.

Holt, N. L., Tink, L. N., Mandigo, J. L., \& Fox, K. R. (2008). Do youth learn life skills through their involvement in high school sport? A case study. Canadian Journal of Education/Revue canadienne de l'éducation, 281-304. 
STUDIA SPORTIVA 2021/2

Kannekens, R., Elferink-Gemser, M. T., \& Visscher, C. (2011). Positioning and deciding: key factors for talent development in soccer. Scandinavian journal of medicine \& science in sports, 21(6), 846-852. https://doi.org/10.1111/j.16000838.2010.01104.x

Kuraizi, Ali, (2008). he relationship of psychological skills and motivational traits among young basketball players in Maysan Governorate, Journal of Faculty of Education, 1 (4), P. 250-269

Kumar, S \& Bhukar, J.(2013). Stress level and coping strategies of college students. Journal of Physical Education and Sports Management, Vol. 4(1): 5-11.

Maqableh, M. (2019). The Effect of a Proposed Training Program on Some Elements of Physical Fitness for Athlete Training Course Students at Yarmouk University, unpublished PhD theses, University of Jordan.

Mohammadzadeh, H., \& Sami, S (2014). Psychological Skills of Elite and Non-Elite Volleyball Players. Annals of Applied Sport Science.2 (1):31-36 https://doi.org/10.18869/acadpub.aassjournal.2.1.31

Nijmah, B., (2014), Emotional Intelligence in relation to self - confidence for college Students, Mawloud University, Algeria

Taber, K. S. (2018). The use of Cronbach's alpha when developing and reporting research instruments in science education. Research in Science Education, 48(6), 1273-1296. DOI 10.1007/s11165-016-9602-2

Tarawneh, Asefa (2016). Emotional Intelligence and its Relationship with Self -Confidence for Field Training Students in Schools of Physical Education at the Jordanian Universities. unpublished Masters thesis dissertation, Mu'tah University.

Wahdan, N. (2011). The Development of a Psychological Training Scale for Female Swimming Field Training Course, Assiut Journal of Sports Education Science and Arts, 3 (33).

Weinberg, R. S., \& Gould, D. (2018). Foundations of sport and exercise psychology, 7E. Human Kinetics.

Wirthwein, L., Sparfeldt, J. R., Pinquart, M., Wegerer, J., \& Steinmayr, R. (2013). Achievement goals and academic achievement: A closer look at moderating factors. Educational Research Review, 10, 66-89. https://doi.org/10.1016/j. edurev.2013.07.001

Younes, M. (2015). The role of attention in improving some defensive skills of volleyball players, unpublished Masters theses, Mohammad Budiaf University, Algeria.

Yousef, Hussein, (2015). Level of Psychological Skills amongst Volleyball Players in The West Bank-Palestine, Masters thesis dissertation, AINajah National University

Yeung, W. (2001). The Performance of Pre-Service Student Teacher (Physical Education) During Teaching Practice in Hong Kong. A paper Submitted for Discussion at 21 International Seminar for Teacher Education (ISTE), College of Education, Kuwait.

Zaki, A. (2010). The Development of a Psychological Scale for Female Gymnasts, unpublished Masters theses, University of Zaqaziq, Egypt.

Zubeidi, M. (2011). The effect of a psychological skills program on creating optimal psychological energy, level of achievement, and psychological performance of young soccer players, unpublished Masters theses, Iraq. 